\title{
MUERTE Y DESNUDEZ EN LA EXPERIENCIA DE LA VOCACIÓN
}

\section{DEATH AND NAKEDNESS IN THE EXPERIENCE OF VOCATION.}

\author{
Mátyás Szalay ${ }^{1}$ \\ Instituto de Filosofía Edith Stain (España)
}

\begin{abstract}
Resumen: Este breve ensayo complementa en aspectos esenciales la argumentación de mi libro Introducción a la filosofía de la vocación en la medida en que se analiza la experiencia de la vocación desde el punto de vista de la estética. Me centro en cinco preguntas con respecto a la obra de Felice Casorati titulada Vocation. Primero, partiendo del título de la obra en relación con la desnudez de la figura ilumino la diferencia entre una interpretación santa y profana. En el segundo capítulo intento captar y describir el sujeto de la vocación, uno de las protagonistas de este drama. El tercer capítulo está dedicado a caracterizar el contexto de la vocación con atención especial a la esperanza. El siguiente punto trata del análisis de la experiencia temporal de la vocación. El quinto paso es un nuevo acercamiento a la pregunta más esencial: ¿quién es el que llama en la vocación? El último punto es una recogida de los resultados, es decir, aquellos aspectos esenciales que nos sirven como puntos orientativos para vivir y expresar mejor la vocación como pleno sentido de la existencia.
\end{abstract}

Palabras clave: VOCACIÓN; FILOSOFÍA; ESTÉTICA; MUERTE; DESNUDEZ; CASORATI

Abstract: This short essay is supposed to complement the argumentation of my book, Bevezetés a hivatásfilozófiájába [Introduction to the philosophy of vocation], concerning an essential aspect for it analyses the experience of the vocation from the point of view of its peculiar aesthetics. By interpreting Felice Casorati's painting entitled Vocation I focus on five aspects. First, concerning the nakedness, I illuminate the relation between saint and profane. In the second part, I try to grasp the subject of the recipient of vocation, i.e. one of the protagonists of this dramatic encounter. The third point is dedicated to the question of the meaning-context of vocation. I argue that it is essentially characterized by hope. The fourth chapter describes the specific time-experience

[1] (szalayster@gmail.com) Actualmente es el Director del Instituto de Filosofía Edith Stein, campus de la Academia Internacional de Filosofía en España. Profesor asistente en la Academia Internacional de Filosofía-Instituto de Filosofía Edith Stein y el Instituto de Teología «Lumen Gentium» (Granada). Mátyás Szalay completó su doctorado en filosofía en la Academia Internacional de Filosofía en Liechtenstein y estudió filología alemana. Ha publicado numerosas traducciones, así como artículos sobre amistad y conversión. Asistente de redacción de «Anthologie der realistischen Phänomenologie» $\mathrm{y}$ «Realist Phenomenology». Autor del próximo libro «Philosophari in Maria». 
of vocation. As a fifth step once again I ask the main question here: who calls in the vocation? The last point summarizes those five essential aspects that could help us to live and to manifest the vocation as the fullest meaning of our existence.

Key words: VOCATION; PHILOSOPHY; AESTHETICS; DEATH; NAKEDNESS; CASORATI

«Queridos hermanos, nuestra tarea más grande en esta vida es sanar la visión del corazón para que pueda reconocer a Dios.» (2)

¿Cómo se puede analizar la estructura estética de la vocación? ¿Cómo aparece la vocación en su forma concreta? es decir, ¿en qué consiste lo específico de la expresión corporal, lingüística, cultural de la persona llamada? Indudablemente se comprende más profundamente la esencia estética de un fenómeno a través de su representación artística. La historia del arte conoce muchas obras extraordinarias cuyo tema es la vocación. Es menester eligiendo una, escrudiñarla de forma filosófica para ver cómo irrumpe en nuestra vida y cómo se constituye aquel sentido especial que es capaz de trasformar completamente todas nuestras relaciones básicas

La elección de Vocation (1939) (3) firmado por Felice Casorati no es arbitraria, sino se debe a la profundidad filosófica y riqueza intelectual de esta obra. Lo que nos deja estupefactosa primera vista es la verdad de la desnudez de la figura femenina que tanto nos ayuda a sentirnos sin herramientas y sin velos a la hora de enfrentarnos con la pregunta de la vocación. Es este motivo provocador y llamativo el que nos abrirá los diversos niveles de significado acerca de la esencia de la vocación.

El presente ensayo introductorio queda lejos de iluminar el fenómeno de la vocación como lo abordarían las obras de arte. Pues el filósofo no puede más que dejarse instruir con la humildad del discípulo por la representación artística que, con singular concisión, ofrece las verdades expuestas hasta para los sentidos. No es este un caso especial, sino más bien se trata del exceso propio del arte comparándolo con la dialéctica filosófica.

Este exceso de riqueza sapiencial del arte aparece a su vez como una exigencia moral para la filosofía: a la hora de la recepción de la obra del arte se debe explicar en qué consiste exactamente. (4) La representación artística de la vocación nos invita e inspira una contemplación cuyo objeto es la encarnación de aquel sentido personal que fundamenta y compenetra toda nuestra vida.

Como itinerario he elegido cinco aspectos fundamentales ofrecidos por el cuadro de Casoratipara entender mejor el misterio que encierra la encarnación de la vocación; dichos aspectos caracterizan la vocación de 
forma substancial. Primero, partiendo del título de la obra en relación con la desnudez de la figura, el cuadro nos guía de una interpretación profana hacia una comprensión de la vocación en términos religiosos. En el segundo capítulo intento describir el sujeto de la vocación, uno de losprotagonistas de este drama. El tercer capítulo está dedicado a caracterizar el contexto de la vocación con especial consideración a la esperanza. El siguiente punto trata del análisis de la experiencia temporal de la vocación. El quinto paso es un nuevo acercamiento a la pregunta más esencial: ¿quién es el que llama en la vocación? El último punto ofrece un resumen sistemático de los resultados, es decir, aquellos aspectos esenciales que nos sirven como puntos orientativos para vivir y expresar mejor la vocación como pleno sentido de la existencia.

\section{El titulo: ¿se puede representar la vocación?}

El titulo del cuadro (Vocation) y su contenido se encuentran en una peculiar tensión. ¿Se podría adivinar a qué se refiere la representación sin el contexto interpretativo ofrecido por el título? Y, por otro lado, conociendo el titulo ¿no es muy curiosa esta figura femenina con su peculiar mirada? ¿En qué sentido se tematiza aquí la vocación? Ciertamente está claro que no se trata, por ejemplo, de una doctora agotada por su servicio o de una profesora concienzuda que por trabajar hasta quedar exhausta cayó de rodillas quitándose justo la ropa. El cuadro, con su determinación sencilla, no funciona como una fotografía (5); más bien nos invita a desvelar, trascendiendo lo que representa y también aquello a lo que se refiere. $\mathrm{Al}$ mismo tiempo se cierra frente a todas las interpretaciones que parten del acercamiento cotidiano (pre-filosófico) de la vocación que excluyen o no tienen suficientemente en cuenta su dimensión espiritual. Frente a una mirada más apropiada, sin embargo, se ilumina de repente el camino quizás fastigoso, que he recorrido a través de la argumentación filosófica con mi libro desde el concepto de la vocación como profesión a la comprensión de la vocación (6) como un destino personal y una llamada universal.

Primero, el cuadro ilumina que no se trata de una vocación, sino de la vocación y, lo que es más, no de una cierta persona - y permitásenos añadir de una mujer - sino de la persona humana.

La composición bien elaborada se cierra herméticamente frente de las interpretaciones erróneas y no deja reducir el campo interpretativo de la vocación en ninguna dirección. Si lo intentamos, es decir, si reducimos forzosamente el sentido de la vocación, la sencillez de la situación representada camufla los profundos contenidos filosóficos que aparecenante nosotros como irrelevantes y sin sentido. Ellos se muestran al intérprete 
si este se detiene frente a esta visión sin pretender nada.(7) Esta mirada obediente y contemplativa que no mira al cuadro desde el concepto cotidiano de la vocación, sino que más bien se acerca a la realidad con una visión re-orientada por el contenido filosófico del cuadro, puede revelarnos la estructura esencial de la vocación.

Entonces, no se trata de que nos dediquemos a una pregunta que carece de importancia: ¿de qué tipo de vocación-profesión se trata aquí?, sinomás bien de que nos acerquemos al cuadro buscando el sentido más profundo de la vocación que no excluye un carácter religioso, puesto que la obra nos ofrece más apoyos. Aunque no se ve ninguna referencia directa al respecto(por ejemplo, no hay un crucifico colgado encima de la pared), la dimensión sagrada de la vocación está presente de manera notable: lo sagrado aquí no se separa de la esfera profana, sino más bien la compenetra. Las manos cruzadas pueden descansar encima de la Biblia como también encima de cualquier obra literaria, puesto que en el contexto de la vocación incluso esta se eleva en cierto modo hasta la dimensión de los textos sagrados. Ciertamente el sentido de la postura de estar de rodillas (8) también desvela más su sentido, siempre y cuando lo interpretemos como un gesto de reverencia. También el lugar promueve este tipo de interpretación aunque no se trate de una iglesia, sino más bien del interior de una celda. No menos relevante es el hecho que la figura femenina reposa encima de una mesa como si esta fuera un altar.

Aunque hay relevantes refencias a lo religioso, no tienen una denotación concreta; el conjunto de la composición da lugar a una incertidumbre interpretativa y nos vemos forzados a oscilar entre el campo de referencias profano y sagrado. Esta indefinición, o mejor decir este movimiento espiritual o intelectual en la esfera de lo simbólico, que es a su vez santo y profano, es un concomitante de la belleza artística. El sentido del cuadro que se revela paso por paso es, al mismo tiempo, un misterio y una promesa que nos atrae y pone en movimiento el espíritu y el alma. Contemplado desde el punto de vista de la vocación, el movimiento del alma inducido por la belleza se entiende como una dinámica de ascensión y de descenso (9) en la cual lo sagrado aparece como una realidad corporal y concreta mientras que lo cotidiano de la realidad se enaltece.

El punto de partida de esta dinámica sigue siendo la «interpretación literal» del cuadro. La sencillez de la representación y su reticencia puritana hasta cierto punto corroboran la narrativa simplista según la cual no se trata de otra cosa que de una mujer leyendo un libro, que quizás por el efecto del texto,cae de rodillas y con conmoción evidente se pone a pensar o, incluso, a rezar. Lo que nos traslada a otro terreno (lo que Han llama una 'grieta') es la peculiar desnudez de la mujer (10) que no es ni 
pomposa, ni frívola; ella no lo hace de manera impertinente, sino con la ingenuidad y naturalidad de los niños. Este abrirse del cuerpo femenino nos resulta sorprendente, sin causar consternación. Por la mirada suave y extrañada, por la postura encorvada del cuerpo, como también por su espalda arqueada y su columna vertebral medio inclinada, la figura nos invita a pensar más que a escandalizarnos: ¿cuál es la razón de esta desnudez pasmosa? En vano se busca en el cuadro cualquier elemento de justificación. Lo que provocó (pro-vocación) el desvestido o, mejor dicho, quién lo encausó, no puede estar representado como entidad autónoma; si está en algún lugar, está ahí en donde la mirada de la mujer se pierde.

Está claro entonces, que la desnudez de la mujer no es ninguna frivolidad (11), ella no está despojándose ni desnudándose (12) y, sin embargo, se quitó toda su ropa frente a alguien. La persona que provocó su desnudez se hace presente justamente porque no aparece... Pues la composición formula una pregunta cuya respuesta se encuentra solo fuera del cuadro: ¿quién es la persona que justifica y permite este desvestimiento? Fijándonos bien en el peculiar carácter de su desnudez, se podría plantear, no sin cierto atrevimiento, la tesis de que no hay persona humana frente a la cual una mujer pueda arrodillarse de esta manera: con la sorprendente naturalidad y la inexpresividad significativa de entregarse plenamente. Así es como la dimensión religiosa y trascendente del cuadro se hacen valer, sobre todo, a través de la desnudez aparentemente injustificada.

Quizás, precisamente, en esta religiosidad temerosa e implícita se esconde una de las más grandes verdades del cuadro: que la dimensión de la vocación aparece sin que sea necesario apoyarse en un símbolo religioso (13); su relevancia se hace evidente cuando la desnudez inexplicable le hace, en su ausencia, presente a Él, quien nos llama desde la experiencia de la vocación. Esta dimensión latente de la religiosidad puede resaltar desde lo profano en cualquier momento y lugar, precisamente porque lo fundamenta (sostiene) y completa lo profano en todos los tiempos y lugares. El que llama de repente se hace presente y lo hace como alguien que ya desde siempre ha estado ahí llamándonos. Aunque él mismo no es inmediatamente visible es ciertamente real; no coincide con lo visible pero su presencia tampoco es independiente de ello, puesto que se manifiesta en ello. Esta manifestación de lo visible en lo invisible es el trasfondo de todas las vocaciones y la obra del arte nos ofrece un testimonio especial de tal hecho.

Como bien indica el título dela obra, La vocación, se trata sobre todo de representar lo invisible a través de lo visibley lo que aquí se tematiza como ‘Él que llama dentro de la vocación', y frente a quien la mujer se 
desnuda y misteriosamente cae en sus rodillas. A través de fijarnos en la parte más visible de esta relación, la persona llamada, es posible acercarse a Él, que llama.

\section{Cierta femineidad que esencialmente caracteriza al acoge- dor o receptor de la vocación}

El detalle quizás más curioso de la figura femenina de color hueso que ocupa el centro del cuadro son los ojos oscuros que casi desaparecen en las órbitas negras. La mujer no mira a nada y, sin embargo, ella es atención pura; aunque los ojos no buscan ningún aspecto concreto, son totalmente receptivos. Ven aunque no lo miran: en los ojos brilla la oscuridad luminosa. La cabeza girada al lado expresa esta misma tranquilidad: reposa flácida encima del borde de la mesa que está cubierta de libros. El pelo negro está recogido atrás en una coleta bien ordenada, la nariz se hincha y los labios se parten. La línea de la columna vertebral, los hombros relajados y toda esa paz casi irreal invoca aquel momento cuando se le abre al hombre una nueva dimensión de vida por la realidad irrepresentable por y a través de la vocación.

El momento de la recepción conlleva la posibilidad de una transformación; quien luego se levanta es otro al que en un primer momento se puso de rodillas. El cuadro capta con agudeza el momento de 'sístole' del corazón, o con la palabra de Proust, las intermitencias del corazón (les intermittences du cœur) (14), cuando no late por sí-mismo por reflejo, sino dejando una cadencia, después de la muerte momentánea, y empieza a latir con un ritmo diferente. Es este momento dentro de lo temporal pero fuera del tiempo experimentado, cuando el cuerpo reposado, que recibe el logos y se lo apropia como el sentido de su vida, recobra sus fuerzas y se encamina hacia su nueva misión.

Hay algo inimitablemente femenino en el modo en el que el alma en el cuerpo se abre frente a algo invisible e inefable. No podemos afirmar que las mujeres por lo general sean más receptoras que los hombres (como si existiera una manera de corroborar la veracidad de tal generalidad); no se trata aquí de una comparación entre los sexos. No es la femineidad que es receptiva, sino que más bien la receptividad es de tipo femenino (15); el modo de acoger el secreto que se nos comunica en y a través de la vocación queda illuminado por el misterio del cuerpo femenino. Desde la fina corvadura de las pestañas hasta lo blando del abdomen,todos los aspectos del cuerpo de la mujer nos revelan la misma verdad profunda y, a su vez, elevada: la apertura fundamental de la persona humana a aquelloque le 
supera y le transforma. (16) En el encuentro entre Dios y los hombres lo humano es receptivo; es esta receptividad la que nos revela la femineidad desde la acogida y a través de la donación de sí misma hasta la fecundidad.

Independiente de nuestra identidad sexual, todos recibimos la palabra que nos llama, en cierto modo como mujeres, es decir de manera femenina, y después de habernos renovado corporalmente por completo, todos asumimos nuestra misión como hombres (con el coraje de los destinados a muerte y, si hace falta, incluso contra todo el mundo). Las llamadas tienen que estar recibidas y llevadas al corazón para que se transformen en una misión que colabore en trasformar la creación. Con respecto a la vocación, los estados de vida religiosos y laicos se complementan de modo fructífero, tanto como las vocaciones de los dos sexos: mujeres y hombres siempre pueden y deben aprender uno del otro en este sentido: justamente para ser más lo que son, hombres y mujeres. Las virtudes específicas de la espiritualidad-naturaleza femenina y masculina se ligan en todas las vocaciones. Las mujeres viven las virtudes masculinas de modo tan femenino como los hombres se convierten de modo inequívocablemente masculino en seres fieles y obedientes cuando se dejan transformar por el logos que es amor. Por ello, dado que existe una forma de rigor y fuerza particularmente femenina, se puede hablar de una ternura masculina... etc. En este sentido la femineidad de recibir la vocación indica una cierta dirección tanto para los hombres como para las mujeres, aunque de un modo diferente.

La orientación que se señala ahí, es la que los hombres tienen que seguir de modo masculino y las mujeres de forma femenina, es la de vivir la gracia de la muerte. La exigencia que se da a conocer en la vocación en cuanto al mandamientoderenacer solo se cumple por el precio y a través de dar el consentimiento para morir. Se puede asumir la 'muerte' con un espíritu franco y generoso, siempre y cuando uno crea en una vida más plena por haber percibido señales e indicaciones de esta. Para estas personas que tienen la experiencia de un amor que nunca muere, la aceptación de la muerte no es un oportunismo, puesto que ellas viven ya de modo «supratemporalis», es decir, en un tiempo más allá del tiempo.

Es preciso invocar aquí esta sabiduría puesto que el cuadro representa justamente aquel momento de la recepción y entrega cuando el antiguo yo-mismo muere para que pueda resucitar un nuevo y más verdadero yo-mismo. En la célebre unión entre el logos divino y la persona humana, ella se muestra recogida en alma y cuerpo, sin defensa ysin herramientas, pero con una libertad jamás vivida. En esta unión amorosa se experimenta la plenitud y la superación inesperada del anhelo humano; esto exige y permite que se nos llene el alma con el espíritu de la donación y dedicación. El hombre obediente, transformado por amor naturalmente, muere para 
todo egoísmo y toda forma de auto-amor narcisista que situaría su ego por encima del ego del otro. Puesto que ya no vive volcándose en sí mismo y en su abandono queda destrozado este 'yo mismo', siempre fragmentado con una unidad forzada, puede ocupar su plaza algo que nace de forma gratuita desde la relación más fundamental (Dios-hombre); así lo que ha sido imagen y semejanza desde el principio, ahora puede reflejar de nuevo el original.

La representación de la figura femenina nos deja sospechar lo dramático que resulta este enfrentamiento con la muerte y lo difícil que resulta abandonarse en sus brazos. Al mismo tiempo, no se trata aquí de una tragedia, puesto que la muerte no es algo horrible como sería la aniquilación de la vida o del yo, sino que a pesar de todo lo dramático y, justamente por ello, esta muerte es impresionantemente bella. Precisamente, como exigencia sobrehumana, la muerte da espacio y ocasión para la grandeza humana. Morir así es bello porque siempre conlleva la donación amorosa de una vida regalada, o mejor dicho, consiste en devolver la vida a aquello que vive en nosotros y así nos da la vida. La muerte, así entendida, siendo un asunto personal, no es un asunto individual que nos deja solos, sino es par excellence algo interpersonal; es un desbordamiento del amor que invita a una vida en comunión, y por lo tanto,a aquellos que lo reciben y dan su 'sí' les brinda una tranquilidad en alma y cuerpo. (17) La cara sosegada de la mujer expresa esta satisfacción, la felicidad de indigentes ricos.

La figura femenina del cuadro no representa solamente el ser mujer, ni el ser persona humana, sino más bien la naturaleza esencialmente femenina de aqella que recibe la vocación, este es el eterno femenino que vive en todos y que llega a la superficie en y por la vocación. Es este el cuerpo desnudo que está dispuesto a responder el «abrazo mortal» del logos que da una vida nueva; así es la persona que está lista para perderse y, por ende, para encontrarse. Queda claro, pues, que aquello que muere para el mundo (ex-vocación o llamada para dejar el mundo) para vivir para Dios, no pierde el mundo, pues este no se convierte en un lugar vacío desprovisto de interés, como tampoco el tiempo se convierte en la secuencia aburrida de minutos corriendo lentamente, sino todo lo contrario: el espacio-tiempo se muestra como impregnado de Dios. Es el contexto de llamada y misión en lo que se pueden apreciar realmente los medios del diálogo divino-humano lleno de auto-revelación divina. Es en este sentido, siendo la vocación una llamada fuera del mundo, nos invita y urge a meternos más intensamente en el propio mundo, en las circunstancias concretas de espacio y tiempo; toda vocación auténtica es, al mismo tiempo, una in-vocación. 
Precisamente, en este espacio-tiempo, estéticamente muy relevante, es donde se desenvuelve la colaboración entre Dios y hombre - el cuadro escenifica y da forma al reinicio de esta relación drámatica.

La experiencia de la vocación, como vivencia de amor por antonomasia, es espiritual en cuanto incluye la unidad originaria del alma y del cuerpo en la auto-donación. En este sentido la vocación es una plena unión amorosa, es tal desnudez que no admite secretos, porque es la relación misma que se convierte en misterio al ser la manifestación de la relación entre ser y «llegar a ser» (sein und werden). Si uno puede convertirse a sí mismo en los ojos del misterioso y perfecto Otro ¿qué podría o querría ocultar frente a él? La desnudez es a su vez el desocultamiento de la persona que, precisamente gracias a su vocación, es decir, sumergiéndose completamente en esta relación constitutiva, se hace trasparente y se revela a sí mismo en su realidad plena. Cada representación veraz sobre el tema de la vocación es un cierto Ecce homo. Laposibilidad de serasíse fundamenta, sin duda alguna, en el gesto 'arco-creativo' del original e incomparable Ecce Homo. Los llamados, pues, nunca pueden establecer por su cuenta su propia vocación, más bien adquieren el concepto del auténtico yo-mismo dentro de la vocación.

$\mathrm{Al}$ contemplar la figura femenina en el cuadro uno es testigo de un nacimiento especial: se dará la luz a un adulto que está arrodillado con la desnudez del niño frente a su Creador y que se pregunta por el sentido de su existencia personal en el intervalo desde la creación hasta la realidad escatológica. Su desnudez se refiere al hecho de que el hombre es inacabado, puesto que el reconocimiento de la vocación nos obliga justamente a asumir esto. La persona que busca el sentido de sí mismo fuera de sí, es capaz a volver a su origen en la experiencia de la vocación y seguir el sentido personal a través del cual se puede convertir completamente a sí mismo. La tradición Cristiana otorga plena validez a esta experiencia explicando que el último fin de la vocación es completar nuestro ser en Aquello que se hizo hombre por nosotros para que en Él y a través de Su sufrimiento podamos deificarnos (theosis) (18).

La figura femenina, sin embargo, no solo representa un niño nacido nuevamente de rodillas y la persona que se pierde y se encuentra en la auto-donación, sino también a la madre - lo que se ve antes que nada es una madre. Tanto las entrañas de la madre, que se encuentra en el centro de la composición, como también la representación acentuada del pecho colocándolo encima dela diagonal, dirigen nuestra atención al proceso gracias al cual surge una vida nueva del encuentro y de la colaboración divino-humana milagrosamente. La incertidumbre que se introduce con respecto a si la mujer está embarazada o no está más que justificada; si estuviera, 
esto reduciría claramente el sentido universal de la vocación al estar embarazada, dando lugar a la falsa sospecha de que solo la maternidad es la verdadera vocación. El cuadro dice más que esto: toda vocación es de tipo maternal, puesto que todas dan lugar a una vida nueva, tanto para la persona como para todas las diversas comunidades de las cuales forma parte.

La cultura Cristiana sigue atestiguando, de forma más que evidente, la relación esencial entre la vocación y el estado de bendición (embarazo): el origen de nuestra vocación sacramental es la Virgen que recibió el logos divino en su seno. Este hecho no es un mero dogma de fe, sino más bien el dogma afirma una realidad que - una vez revelado - es fenomenológicamente verificable, puesto que su propia lógica se realiza en todas lasautenticas vivencias de vocación. El signo quizás más obvio de esto es que el peculiar logos de la vocación, este sentido que se revela en la experiencia como supra-mundano, original y personal, nunca se puede reducir a la mera información.

Lo que podemos entrever como vocación es un verdadero sentido vivificante, un logos desplegándose de concretos actos de amor que hacen fecunda nuestra vida, siempre y cuando le dejemos penetrar en todas las dimensiones de nuestra existencia y lo cultivemos para luego entregarlo al mundo. Las diversas etapas de criar a un niño, así la concepción-recepción, la nutrición y el crecimiento inter-útero, como también el dar a luz, el cuidado y, al final, el dejar que se vayan para que adultos sean un bien para el mundo, todos y cada uno de estos pasos corresponden exactamente acómo el logos de la experiencia vocacional exige que nos relacionemos con él. Esta relación es alterable, y sin embargo, se le impregna un principio unificador: el sentido personal de la vocación siempre nos invita a relacionarnos consigo mismo maternalmente.

Cuando este sentido se nos presenta con la esperanza de que (al admitirlo) nos llevará a la plenitud, todavía no tiene su forma determinada. No solo la persona a quien se manifiesta, sino también el sentido mismo espera que, al transformarseal sujeto, pueda adquirise una forma, y así manifestándose corporalmente, pueda cambiar de fondo todas las relaciones del yo mismo. Este sentido vocacional, aunque no se origine en nosotros - es esencialmente trascendente -, mientras crece por nuestro amor hacia él, ciertamente vive y se nutre de nosotros. Su ser trascendente también incluye que traspasa a nosotros su propósito. El logos que recibimos no es para nosotros sino para los demás; lo que se presenta como el sentido personal de nuestra vida, tiene «cosas que hacer» en el mundo. Muchas veces las madres mueren dando a luz y están dispuestas a hacerlo 
para que vivan sus hijos. Con este peso drámatico se afirma que el sentido vocacional que hemos recibido como regalo, solo llega a su plenitud cuando es regalado y expuesto libremente a los demás.

Se puede abordar de dos formas distintas la 'fundamental exposición' del sentido de nuestra vocación. La vocación es sobre todo servicio de Dios (lateria theou) (19), por un lado, porqueDios sirve al hombre llamándolo y guiándolo a la comunión con Él y, por otro lado, porque la principal vocación del hombre es responder al amor creativo que lo llamó a la existencia. Los dos aspectos llegan a su expresión más clara y plena en María, en la criatura que se auto-define como esclava del Señor, que 'está ahí' (Ecce ancilla Domini), quien en una situación concreta - sea ella lo que fuera - obedientemente sigue la voluntad de su Señor.

El servicio del amor que surge de la vocación significa a su vez 'estar expuesto'. La mujer arrodillada inclina su cabeza sobre el altar - en lo que se ha convertido la mesa por obra de la vocación - de tal modo que su gesto expresa fragilidad y falibilidad. Lo que invoca el sentido propio de la vocación no es otra cosa que una determinada forma para que se pueda manifestar el amor desbordante. Quien ama y se dona al otro, también se expone a la libertad del otro en toda su fragilidad y su pequeñez insuperable. Analógicamente,la interpretación se nos encomiendan en la experiencia de la vocación es una realidad muy frágil que no nació para triunfar. Las obras sociales que surgen de la vivencia vocacional no aspiran a otro éxito que al ser semilla en el mundo y morir en él como semilla. El fruto que luego puedentraer no es otra cosa que una señal de la fecundidad del amor, gracias a la cual se establece todo un reinado con su orden nuevo: el reino de Dios, civitas Dei. (20)

Entonces quien escucha la palabra que le llama como la figura femenina en el cuadro, será ciudadano de aquel reino y vivirá bajo otra ley y todas sus relaciones reflejarán este orden nuevo.

\section{El trasfondo}

El trasfondo casi desaparece detrás del cuerpo desnudo, pero su estudio promete unos aspectos indispensables para la comprensión del contexto que asume la vocación. La mesa negra cubierta con el mantel verde está puesta entre las antiguas paredes blancas encima del suelo de color tierra. Sobre ella están los libros, a su lado una banqueta de la cual solo se ve una franja. La manta verde poco elaborada cae por las esquinas sobre su peso de manera desbordada como en los antiguos bodegones. En el suelo se ha puesto una manta, alfombra o quién sabe qué cosa negra que 
solo se indica por una mancha negra, por lo que su material solo se puede sospechar. Esta alfombra está cubierta por una piel blanca de oveja que está bajo las rodillas de la mujer.

Como en varios cuadros del pintor la escena aquí es realista en lo que respecta a los objetos que están representados como son en la realidad y al mismo tiempo son organizados como en un sueño. Casorati mismo admitió que lo que pinta es una realidad que surge de dentro; es una verdad tan real y concreta que al mismo tiempo es eterna y no se altera cuando encarnandóse entra en la historia. Cuando el pintor coloca esta verdad de nuevo en el contexto del mundo material intenta acentuar la lógica esencial y, por ende, eterna de las relaciones. Así, Casorati consigue objetivar, a través de la representación, una sensación subjetiva. Atendiendo a los aspectos materiales que nos muestra el propio cuadro, podemos rastrear ciertas "anomalías» (como el tratamiento que recibe el espacio -existe un desajuste entre la perspectiva desde la que se mira y la disposición de los objetos representados- o el uso de los colores combinado magistralmente con las pinceladas -muy alejadas de la realidad). Todo esto nos indica que debemos trascender la propia representación, nos lleva desde lo concreto a lo simbólico-universal, nos traduce una realidad vivida, llevando la referencia más allá de sí misma. En resumen, el pintor es capaz de exteriorizar una verdad interior, purificada hasta lo esencial.

Así la composición es simbólica no a pesar de su concreción, sino justamente por ella; como una realidad vivida, asimilada internamente y a su vez purificada hasta lo esencial, que apunta más allá de sí misma.

En este sentido, el cuadro verdadero nunca es el mero reflejo de la realidad sensual, más bien intenta captar el logos interno de lo visible y exponerlo lo más claramente posible. El dialogo entre lo natural y lo sobrenatural se presenta como una constelación de colores y formas, manchas y líneas, como una composición, un juego organizado y ordenado.

Es importante tener esto en mente a la hora de acercarnos más a la pregunta ¿qué significa en este contexto concreto y a su vez cósmico, en este espacio tanto teológico como metafísico la piel de oveja blanca encima del mantel negro? La elección de los colores, se podría decir, es un problema meramente estético. ¿Pero qué significa esto? Está claro que la estética no significa una técnica para preparar algo espectacular, esto es, no se trata de un gusto individual (sea arbitrario o genialmente universal), sino la manifestación concreta de dicho drama entre el amor divino y humano que se desenvuelve en la historia desde la creación hasta los tiempos escatológicos. 
La piel de oveja blanca puesta encima de la manta negra representa el contraste más aguda y la transición más extrema; cuando la figura femenina está arrodillada sobre ella, no podemos tener ninguna duda: la vocación se expresa como una transición de lo obscuro a la luz, de lo negro del pecado a lo blanco de la piel de oveja. ¿No indica este juego de colores que cada vocación incluya una conversión?

Aunque el contraste blanco-negro sigue reapareciendo en otras partes de la composición, el color dominante es más bien el verde, el color de la sobremesa. El verde encima de las manchas de un suelo marrón se lee tradicionalmente como referencia a la vida de la naturaleza, también signo de esperanza. La experiencia de la vocación ciertamente no sería ella misma sin la esperanza del renacimiento, basada en el reconocimiento de una vida recibida como regalo.

Una auténtica experiencia de la vocación y la de la desesperación se excluyen mutualmente de forma absoluta. Nada puede fundamentar más la esperanza que el sentido que se nos desenvuelve como vocación: hay alguien fuera de nosotros y este alguien nos llama a la felicidad. Y lo que es más,una esperanza desligada del sentido de una existencia personal, siempre será algo infundado y pronto se vaciará y quedará en nada.

Por otro lado, el sentido concreto de la vocación se nos revela precisamente en el contexto de la narrativa de una vida vista y vivida desde la perspectiva de la esperanza. Esperanza aquí, no solo significa una cierta actitud y disposición fundamental, sino también una confianza propia de una relación personal: es esperanza en alguien.

Comprender el sentido de la vocación es llevar a la praxis una hermenéutica de esperanza escatológica. Esto es la conditio sine que non de una vida razonable, ontológicamente fundada y vivida en las relaciones personales y sobre todo en la relación divina-humana; se trata de un logos verificado por experiencias concretas que Horacio lo formuló con precisión en su X Égloga: «Omnia vincit Amor; et nos cedamus Amori». Este «conocimiento» acentuadamente personal y dramático, no está dado de forma $a$ priori, sino que es más bien adquirido a pesar y a través de la dinámica de sufrimiento-caricia divina e humana, alejamiento-acercamiento, culpa y disculpa, decepción y nuevo inicio. En definitiva, no se trata de aquel conocimiento que, una vez adquirido, ya no se vuelve a experimentar sino de un conocimiento que se redescubre constantemente. Este sacrificio de vida peculiar que exige el seguimiento de la vocación, ciertamente puede ser representado e interpretado auténticamente de formas diversas y no solo como una cabeza puesta encima de la mesa-altar. Es cierto, sin embargo, que para captar el sentido de la vocación en su forma concreta, lo que es entender el mandamiento del amor hic et nunc, es necesario verlo en la 
perspectiva de la esperanza última. El peculiar principio de esta visión escatologica necesaria consiste en que no somos nosotros quienes progresivamente se acercan a una felicidad final, sino es el sentido esperanzador el que más bien se acerca a nosotros.

Pues la vida razonable solo es posible en un mundo que, en última instancia, es razonable, en un mundo que no solamente contiene algún tipo de sentido, sino que también está definido y dirigido por el mismo sentido que es la base y el fin de mi propia existencia.(21) En caso contrario, la vida, aunque es gigantesca y heroica, será solo el terreno de una lucha desesperada y solitaria contra las impersonales fuerzas cósmicas. (22)

A su vez, la experiencia vocacional es por ende una experiencia fundamental del mundo, su seguimiento requiere un compromiso por interpretar el mundo e interactuar con él desde una perspectiva escatológica.

\section{El tiempo representado}

¿Puede la experiencia temporal ser representada a través de la pintura? Si se experimenta el tiempo a través del cambio, un cuadro que no es una película (imagen del movimiento), sino que es una imagen del momento o una imagen estática, mientras perpetuiza y eterniza el momento, en cierto sentido cae fuera de lo temporal. Este pensamiento plantea dos preguntas relevantes dentro del contexto actual. ¿Qué esconde y qué es lo que desvela la representación momentánea de la vocación?

Solíamos pensar sobre la vocación en términos de un proceso que se despliega en el tiempo como destino humano. ¿Es posible singularizar y exponer un solo momento de este proceso de tal manera que pueda invocar y hacer presente la compleja estructura del todo el proceso? Esta dificultad se puede ilustrar con la escena del ginecólogo cuando performa la ecografía de un bebé; aunque se trata de una imagen momentánea, en este estado instantáneo (un solo momento de la concepción) para una mirada informada - puesto que lo interpreta como parte de un proceso - se hace evidente el hecho de una vida nueva y se deja entrever su futuro desarrollo.

El cuadro analizado aquí capta de modo semejante el momento inicial que de algún modo ya contiene todo, lo que más adelante se nos revela como vocación en las diversas dimensiones temporales de la historia de la vida. Debido a las limitaciones propias de la pintura, ciertos detalles de este proceso, como por ejemplo los peldaños de la evolución de su carácter dramático, etc. se pierdena cambio de resaltar los fundamentos ontológicos del hecho de que el momento puede contener todo el proceso. 
Aunque se trate de una experiencia muy común, no deja de ser algo que resulta digno de admiración y que resalta que la vida tiene momentos llenos de sentido. Por tanto, estamos ante un fenómeno que requiere una reflexión profunda como la que le brinda San Agustín en su análisis del tiempo. Como es conocido él distingue los modos en que el tiempo se nos da: como presente-pasado, presente-futuro y presente-presente. Estas modalidades de experiencia no están separadas, sino que se refieren mutuamente puesto que están orgánicamente entrelazadas formando parte de una unidad: la narrativa como historia de la salvación (Heilsgeschichte). Puesto que toda vocación forma parte de esta historia, cada momento es trascendente y hace referencia a un ser más allá de sí mismo: por un lado, hacia un 'pasado jamás vivido' (creación) y, por otro lado, hacia'un futuro jamás imaginado' (salvación). Este último es un evento singular de la historia: el irrepetible 'sí' del único llamado que, paradojamente espera ser reiterado por todos nosotros y encontrar su eco en toda la creación. Este 'sí' -según la interpretación Cristiana- es del eterno Logos que, existiendo desde siempre, se encarna en el tiempo para responder a la Eterna Persona Divina. Lo que experimentamos en el tiempo como experiencia de la vocación, se inscribe en este diálogo intertrinitario que comenzó con el exitus, con la secularización de lo divino en la creación, cuyo punto central es el sí dramático de la persona Divino-humana, y su fin es el reditus, el volverse de todas las cosas a su comienzo.(23)

La experiencia de la temporalidad en la vocación es algo radicalmente distinto a la cotidiana experiencia de un tiempo que pasa, o lo que es más, de la fragmentación de lo temporal que San Agustín muy agudamente caracteriza con la metáfora de defluxus (24), un tiempo que difluye y derrama. En la experiencia de lo temporal dentro de la vocación, todo se refiere al comienzo absoluto, y nada es interpretable de forma razonable sin su referencia al fin absoluto, puesto que aquello (la comunidad) es el corazón de la relación amorosa que se dirige hacia aquello que es alfa y omega, comienzo y fin, y quien es por excelencia realidad-presente. Vivir la vocación, vivir para ella y de ella, significa sumergirse en la realidad presente y hacerse presente para aquello que dentro de los momentos efímeros es lo único verdaderamente real y como realidad nos llama a realizarnos, es decir, a desenvolver nuestro verdadero yo.

Solo aquellas personas pueden vivir en esta realidad presente, ya que no se refugian en sus pasados y tampoco se hacen dependientesde sus futuros (25); para tales personasel sentido de su pasado y su futuro se les revela precisamente en la relación con Dios (la futura comunidad escatológica). De alguna forma viviendo ya en relación con la plenitud de los tiem- 
pos nos deja experimentar incluso nuestra vida en toda su fragmentación como un un don pleno para nosotros y, por ende, abre la posibilidad de que sea así también para los demás.

\section{Frente a quién se pone uno de rodillas: Él que nos llama en la vocación}

No sabemos frente a quién se arrodilla la mujer del cuadro, no sabemos por quién es llamada, sin embargo en el modo en que la mujer está de rodillas se nos abre y se nos revela. Esto solo es posible porque el modo en que se revela, es la llamada misma.

A lo largo de los tres capítulos anteriores he tratado de sentar las bases de la pregunta fundamental que nos plantea el cuadro: ¿quién es el que llama en la vocación? Al contrario de lo dicho previamente, esta pregunta no solo introduce el cuadro, es decir, no solamente invita a contemplar los detalles, sino que también nos guía fuera del cuadrode manera más intensa que cualquier otro aspecto tratado... Estamos ante una pregunta que no puede contestarse apoyándose únicamente en el cuadro: nos exige un testimonio personal. Así, el cuadro participa de una dinámica mucho más amplia y fundamental propia de la vocación y que deja aparecer la pregunta por quién llama en la vocación sin darnos excusa para no-contestarla, puesto que incluso denegar la respuesta ya es una respuesta.

La dinámica de la vocación se manifiesta en el deleite estético que llega a su plenitud cuando nos reconocemos en la mujer que hemos identificado como la naturaleza de la persona llamada y este reconocimiento nos lleva a dar un testimonio personal poniéndonos de rodillas a su lado. Este gesto es un prerrequisito para que se manifieste Aquél que llama en la vocación. Solo un sí espiritual-corporal puede asimilar esta apertura al origen.

Asumir la responsabilidad de la respuesta no es cumplir con una obligación ineludible. (26) Se asemeja más bien a aceptar una invitación. El que llama en la vocación revelándose, nos invita a acercarnos a Él. Y la auto-revelación divina es una invitación porque siempre es amor, un amor que no se puede dejar sin respuesta, un amor exigente. Quien llama, es el mismo que quien ama,cuyo ser y existencia coinciden porque es el amor mismo. Él que llama se deja identificar porque su amor por nosotros es siempre más grande (Deus semper maior), siempre sobrepasa los limites sin experimentar este exceso de alguna forma no se puede hablar de una autentica vivencia vocacional sino más bien de una deformación de ella con consecuencias trágicas para la persona y sus comunidades. En el sen- 
tido estético, es decir, examinando la forma básica de aparecer la vocación desde los sentidos siempre es una cierta forma de amor o, mejor dicho, es un acto de amor que surge desde el orgien y está orientado hacia él.

Es este amor majestuoso que deja caer el sujeto de la vocación de sus rodillas - ninguna respuesta es suficientemente buena para contestarlo y sin embargo tenemos que responderle con todo nuestro ser. El centro del cuadro nos señala esta curiosa paradoja: el gesto de arrodillarse. Desde luego este gesto no es de una persona humillada; la escena se estructura por otra lógica. Solo la persona que se arrodilla por su libre voluntad puede enaltecerse de forma tan profunda. Así, la persona amada deja, de rodillas, que el amor le cubra completamente y le traspase como una ola gigantesca que inunde todo.

La tesis correspondiente de la representación se podría formular de la siguiente manera: Él que llama en la vocación solo se puede ver bien de esta perspectiva de arrodillarse. Sobre todo porque aquí se puede experimentar que Él se ha agachado y que se expuso completamente para que nosotros podamos disponer de Él libremente. Es Él quien incluso en su pequeñez es grande y exponiéndose reina sobre nosotros; apoyándonos desde abajo a la hora de caer de rodillas. Es esta una de las paradojas del sentido de la vocación.

\section{Resumen: ¿hasta qué punto el cuadro ilumina la estructura esencial de la vocación?}

Lo que entiendo aquí bajo el termino de estructura esencial de la vocación,en su dimensión estética, es el modo enque la vocación se manifiesta y llega a ser expresada en la persona llamada y sus relaciones. Todas las expresiones de la trasformación son relevantes como posibilidades existenciales y formas concretas de llevar la vida (Lebensführung) para aquellos que intentan ser fieles al sentido transcendente. Este se puede entrever en la experiencia de la vocación provocándonos de tal manera que es a su vez in- y ex-vocación, es decir al llamarnos fuera de lo mundano y llamarnos a penetrar la realidad creada. El surplus del sentido que se presenta en la vocación es exigencia y desafío: tenemos que descubrir aquella forma en la cual se exprese todo lo que ocurre como el amor mutuo que surge en el encuentro dramático entre Dios y hombre. Es este el espacio de la libertad. Aquí se vive la libertad sin concesiones puesto que la libertad no es posesión de una persona sino característica de una relación. ¿Existe, entonces, en esta libertad vertiginosa,elementos formales esenciales e indispensables para vivir plenamente la vocación? 
El cuadro de Casoratipuede iluminar algo esta pregunta. A lo largo de nuestro análisis hemos encontrado al menos cinco aspectos esenciales que funcionan a modo de punto de apoyo para vivir y expresar la vocación como el sentido pleno de la existencia.

Primero, se puede señalar la necesidad de la desnudez. Afirmo entonces que toda expresión autentica de la vocación tiene el rasgo distintivo que fundamenta la relación divino-humana íntima hasta lo corporal en la que el hombre dice un sí sin máscaras al sentido personal que dicha experiencia ofrece.

Segundo, la expresión de la vocación es siempre dramática: nace a través de un encuentro en el que las dimensiones profanas y santas se inter-penetran y se dejan impregnar mutuamente.

Tercero, la persona destinataria/receptora de la vocación tiene que estar necesariamente de rodillas, es decir, espiritualmente tiene que adoptar la actitud fundamentalde humildad ontológica y pobreza que caracteriza el modo preciso de vivir la asimetría de esta relación dramática. Esta lógica peculiar tiene que definir toda la estética de la vocación.

En cuarto lugar, todas las expresiones de la vocación son esencial y necesariamente narrativas. La misma narratividad sin embargo es solo una forma de cómo aparece en la experiencia de la vocación la vivencia propia de la temporalidad. Puesto que podemos experimentar la temporalidad, especialmente, como 'tiempo de la vocación', la vivencia vocacional (Erlebnis) siempre designa aquella forma temporal y aquel mundo de tal manera que se pueda experimentar (Erfahrung) y vivir (Leben) la vocación.

Por último y, probablemente lo más importantemente: aunque la experiencia de la vocación siempre conlleve el descubrimiento de un nuevo 'yo-mismo' o,dicho de otra manera, el redescubrimiento del auténtico 'yo-mismo', lo fundamental no es esto, ni siquiera la santidad del yo que ocupa su centro, sino aquello que se revela en la vocación como Quién nos llama. Toda manifestación estética de la auténtica vocación está determinada por este movimiento esencial que del yo se dirige hacia el Tú-eterno, al origen que se da a sí mismo como amor.

\section{Notas}

1 Agradezco enormemente los consejos y correciones de Feliciana Merino Escalera y Jorge Martinez Benda.

2 San Agustin, Sermo. 88.6 PL 38542. in: D. L. Schindler, Hans Urs von Balthasar: his life and work, (Ignatius Press, 1991) 43. 
3 G. Bertolino, F. Poli, V. Carioggia, «Memorie su Felice Casortai» (Canale Arte, 2013) en: https://www.youtube.com/watch?v=RTjy6yCRMNQ (2016.08.08.)

4 Aquella postura filosófica que menosprecie las artes comete un error moral, puesto que todo el bien que posiblemente es capaz de recibir y expresar solo se manifestaría privado de su belleza (kallos). Pero ¿puede algo ser bueno sin ser bello a su vez? ¿A caso la bondad no es para nosotros el grito de la belleza tal como indica su etimología? Quien no escucha este grito (kalein) tampoco será capaz de captar la bondad. Cf. P. D. Areopagita, «De divinis nominibus», en B. R. Suchla (dir.), De divinis nominibus (Walter de Gruyter, 1990), IV, 7, 135.

La co-pertenencia originaria de la bondad y la belleza no solamente está señalada por el concepto griego de kalokagathia ( $x \alpha \lambda$ ox $\alpha \gamma \alpha \theta i \alpha)$, sino que también - y con incomparable claridad - lo expresa la tradición Cristiana al insistir en los trascendentales: unum, bonum, verum, pulchrum. Conlaspalabras de Guillermo de Auxerre: "Idem est in ea (substantia) ejus bonitas et ejuspulchritudo..." "Penes haec tria (species, numero, ordo), est rei pulchritudo, penes quae dicit Augustinus consistere bonitatem rei."(lo cita, U. Eco Arte y belleza en la estética medieval (Editorial Lumen, Barcelona, 1997) 44.)) Véansetambién: J. L. ChrÉTIEn, The call and the response. No. 33. (Fordham Univ. Press., 2004); y también: H. Balthasar, Herrlichkeit: Schau der Gestalt. I. (Johannes Verlag, 1961).

5 H. Byung-Chul, Transparenzgesellschaft (Matthes\&Seitz, Berlin, 2012); H. Byung-Chul, Die Errettung des Schönen(Fischer Verlag, Frankfurt am Main, 2015).

6 F. Merino Escalera, «La vocación de la mujer y el feminismo de Edith Stein", en Cuadernos de Pensamiento: Vol. 13. (1999)93-109.

7 La representación pictórica difiere justamente de la fotografía en que la primera invita y da lugar a „morar» (to dwell) que es lo propio de la contemplación. El «cómo» de la representación se refiere a un contexto del sentido, que no se puede recibir de forma taxativa, es decir no es suficiente la enumeración de los entes como tal; se debe entender también cuál es el sentido escondido que nos señalan. Este contexto de referencia se deja entrever poco a poco e incluye al espectador en esta esfera vivificante. Por esto puede escribir correctamente Rilke en su poema Torso de Apolo Arcaico que al mirar la obra del arte tenemos que cambiar nuestra vida ( $D u$ mußt dein Lebenändern), es decir, toda la belleza artística nos brinda la posibilidad de una nueva vida concebida en la belleza. véase: R. M. RILKE, "Archaischer Torso Apollos", en R. M.RILke, Werke in drei Bänden, Vol. 3. (Insel, 1966); H. L. KessleR, «Turning a Blind Eye: Medieval Art and the Dynamics of Contemplation", en The Mind's Eye: Art and Theological Ar- 
gument in the Middle Ages (Department of Art and Archaeology, Princeton University, 2006) 413-439.; R. G. Collingwood, The principles of art. Vol. 11. (Oxford University Press, USA, 1958).

8 H. Balthasar, «Theology and Sanctity», enThe Word Made Flesh (San Francisco, 1989) 181-209; P. HenRICI, «Hans Urs von Balthasar: A Sketch of his life», en D. L. Schindler (dir.), Hans Urs von Balthasar: His Life and Work (Ignatius Press, 1989) 7-44.; J. H. McKennA, «Theology of Adoration", en: Vincentiana, 49/1, (2005), Article 16.

9 Sobre la dinámica de ascensión y descenso, Platón ofrece una descripción detallada en más de un diálogo (véanse especialmente el libro VII de la La República y el Fedón), esta idea, sin embargo, se profundiza de forma incomparable en la cultura Cristiana, donde la medida y el camino es la Encarnación de Cristo, su descenso a los infiernos y su resurrección para compartir la gloria con el Padre. En general la relevancia del arte consiste en captar este camino circular o itinerario completo y sus diversos peldaños. Es un hecho llamativo que la tarea especial del arte Cristiano - siempre y cuando intente evitar quedarse en lo superficial y, por ende, perder su relevancia- consiste en representar la belleza, siempre desafiante, que casi se define por la escena histórica donde se revela sobre el Crucificado la gloria de Dios. El sufrimiento más grande y la catástrofe más cósmica se abre camino hacia la impensable manifestación divina de la belleza. Esta paradoja fundamenta quizás la tarea más curiosa para los artistas Cristianos: tener que bajar hasta los infiernos, puesto que es el Logos mismo quien les iluminó esta esfera del mundo cuando Él mismo descendió a las moradas de todos los sufrimientos para cargarse de los pecados (descendit ad inferos). H. Balthasar, «Adrienne von Speyr: Über das Geheimnis des Karsamstags", en: Internationale Katholische Zeitschrift Frankfurt (1981), 10/1, 32-39.; H. BALTHASAR, Theologie der drei Tage (Johannes-Verlag, 1990).

10 La problemática de la representación de la mujer desnuda ha acompañado a Casorati a lo largo de toda su vida profesional; es un motivo recurrente de varios cuadros tanto de su época naturalista como simbolista. G. Bertolino, F. Poli, V.Carioggia, «Memorie su Felice Casortai» (Canale Arte, 2013) en: https://www.youtube.com/watch?v=RTjy6yCRMNQ (2016.08.08.)

11 La relación entre desnudez y vocación no es nada arbitraria. El cuadro aquí analizado se refiere a una tradición viva y su sentido propio se nos desvela desde esta perspectiva. De esta herencia cristiana se pone de manifiesto especialmente el tema de „Nudus Nudum Christum sequi». Se suele atribuir esta formulación a San Jeronimo (331-420), padre latino de la Iglesia, pero la idea se puede rastrear hasta Lactantius. El pasa- 
je bíblico relevante es sin duda alguna el Mt 19, 21 y encontró más eco entre los pobres de Cristo (pauperes Christi), es decir, los franciscanos, los representantes de los norbertinos y los cistercienses. Antes que nadie es San Bonaventura quien lucha por esta interpretación del imitatio Christi. en J. Chántillon, «NudumChristusnudussequere. A Note on the Origins and Meaning of the Theme of Spiritual Nakedness in the Writings of S. Bonaventure», en S. Bonaventura 1274-1974 4. vols. (Grottaferrata Collegio S. Bonaventura, 1974) 719-772.; R. GRÉGOIRE, «L’adage ascétique 'Nudus nudum Christum sequi", en Studi storici in onore di Ottorino Bertolini, 1. vol. (Pisa, Pacini, 1972) 395-409.; F. Morando, «Nudusnudum Christum Sequi. The Franciscans and Differing Interpretations of Male Nakedness in FiftheenCentuary Italy", en E. E.DuBruck, B. I. Guisick, Fiftheen Century Studies. Vol. 33. (CadmenHouse, Suffolk, 2008), 171-198.

12 En español es difícil señalar la distinción que existe, fenomenológicamente, entre las dos formas de la experiencia de la desnudez. En inglés, al menos en la interpretación de Kenneth Clark, se puede notar una diferencia entre „nudity» y „nakedness». „En breve, estar desnudo [to be naked] se refiere a estar desabrigado y este concepto se refiere a la vergüenza que solíamos sentir en este estado.» "La desnudez [nude], por contraste, no se refiere tanto al cuerpo indefenso y frágil, sino más bien a la sensación corporal de estar equilibrado, fecundo y confiado en sí mismo: al cuerpo transformado.» (traducción por M. Sz.), en K. Clark, The Nude. A Study in Ideal Form (John Murray, London, 1956) 84. Está claro que el cuerpo desabrigado se relaciona con dos vivencias distintas y que el idioma es capaz de dar testimonio de esta diferencia esencial solo parcialmente. Por un lado, se plantea una desnudez asociada a la vergüenza del cuerpo desvestido privado de su misterio, que supone la humillación de la persona en su aspecto humano y sexual. Por otro lado, existe otro tipo de desnudez en la que el cuerpo, iluminando un sí completo e incondicional de entrega, es capaz de revelar lo que es humano en cuanto un amor fecundo que no se reserva nada para sí.

13 Para vivir bien la vocación es indispensable un lenguaje simbólico y una interpretación poética del ser. Aquí solo intento señalar que la vocación es una realidad más allá de una religiosidad personal o incluso institucional; es una experiencia de sentido tal que es capaz de vencer toda fuerza y tendencia profetizante y secularizante.

14 M. Proust, Sodome et Gomorrhe (le livre de poche, 2012).

15 Es indudable que la masculinidad de la cara viril de la vocación es igual de receptora que la femineidad. 
$16 \mathrm{El}$ hombre aspira naturalmente a lo sobrenatural - confiesa la tradición Cristiana. Sobre el trasfondo teológico de este pensamiento: H. DE LuBAC, Le mystère du surnatural (Editions Aubier Montaigne, Paris, 1965).

17 B. Blesan, "Devenir cuerpo en la sociedad de consumo", en Revista Internacional de Filosofia, No 66 (2015) 121-133.; Sobre recuperar las metáforas de lo corporal véanse F. HADJADJ, La profondeur des sexes: pour une mystique de la chair (du Seuil, 2008); J. M. FidALGo, «Fabrice HADJADJ, La profundidad de los sexos. Por una mística de la carne, Granada: Nuevo Inicio, 2010, 302 pp.» en ScriptaTheologica 44/1(2015) 259.

$18 \mathrm{El}$ concepto acuñado por Origenes ha sido más elaborado por los padres capadocios y sobre todo por San Gregorio de Nisa y Maximus Confessor. Una buena definición de la expresión podría ser esta: la theosis es «el proceso de santificación en el cual los Cristianos gradualmente se asemejan a Dios; la última prueba de esta asimilación es la gloriosa transformación de los justos en el Reino de Dios, cuando en la glorificación de los fieles (acoD) se muestra claramente la inmortalidad y la contemplación más perfecta de Dios. Véanse: M. Christensen, J. WitTung (dir.), Partakers of the Divine Nature. The History and Development of Deification in the Christian Tradition (Farleigh Dickinson University Press., 2006), enhttp://www.sgtt.org/ Writings/Patristics/Deification.html (07.10.2016).; AtHanasius De Incarnatione. 54 en E. P. Meijering, Saint Athanasius, J. C. M. van Winden. Athanasius, De incarnatione verbi: Einleitung, Übersetzung, Kommentar. (JC Gieben, 1989); GREGorio DE NisA, Orationes 29.19: «En la medida en que Él ha llegado a ser hombre, yo puedo convertirme en Dios.»; La idea se suele apoyarse con los siguientes textos bíblicos: Jn 10, 34-36 y 2Pet 1,4.

19 Véase el análisis detallado de este concepto en B. Mezei, Vallásbölcselet. A vallásvalósága (I-II), (Attraktor, Máriabesenyő-Gödöllő, 2004).

20 Es notable que San Gregorio de Nisa describe este radical completarse del Reino de Dios con el concepto usado por Orígenes: «apocatástasis» aunque cambia y corrige su sentido. en J.A. McGuick, «Deification in GreekThought: TheCappadocianFathers' Strategic Adaptation of a Tradition», en M. J. Christensen, A. W. Jefferr, Partakers of the Divine Nature: The History and Development of Deification in the Christian Traditions, (Baker Academic, 2008).Como el autor subraya, la filosofía de Gregorio de Nisa es relevante aquí no solo porque es él también quien consecuentemente cambia el concepto platónico de asemejarse al participar, sino porque es este padre de la Iglesia quien quizás insiste más en que la vocación de la que el hombre participa en la naturaleza humana es convertirse en sacerdote del cosmos. Es esta realidad cósmica, es decir, divinamente ordenada, en la que puede desenvolverse la vocación del hombre.

21 Esta idea está acentuada también por Viktor Frankl. Cf. Frankl 2005. 
22 F. NieTzsche, Über Wahrheit und Lüge im außermoralischen Sinn:[Was bedeutet das alles?], (Reclam Verlag, 2015).

23 Esta expresión que originalmente se encuentra en Plotino, Benedicto XVI la compara con el esquema del Evangelista San Juan, según el cual Jesús es „que había salido de Dios y a Dios iba.» (Jn, 13,3). El descenso de Cristo en la Encarnación afirma la bondad de la creación material como también su asunción (ascensión) al cielo demuestra que la vocación del mundo material es estar presente delante de Dios. J. RATZINGER, Jesus of Nazareth: Holy Week: From the Entrance into Jerusalem to the Resurrection. Trans. Vatican Secretariat of State (Ignatius, San Francisco, 2011).

24 San. AGUSTÍN, Las confesiones (Ediciones AKAL, 1986). especialmente X. libro.; M. HeIDEgGer, Phänomenologie des religiösen Lebens. Gesamtausgabe, Vol. 60. en M. Jung, Th. Regehly, C. Strube (dir.), (Vittorio Klostermann, Frankfurt am Main, 2011). II. Parte

25 Sobre ello nos llama la atención Dietrich von Hildebrand en D. HiLdEBRAND, Die Umgestaltung in Christus. Gesammelte Werke, Vol . 10. (von Hildebrand-Gesellschaft, 1971) 70.

26 H. DE Lubac, Le mystère du surnatural (Editions Aubier Montaigne, Paris, 1965). 
